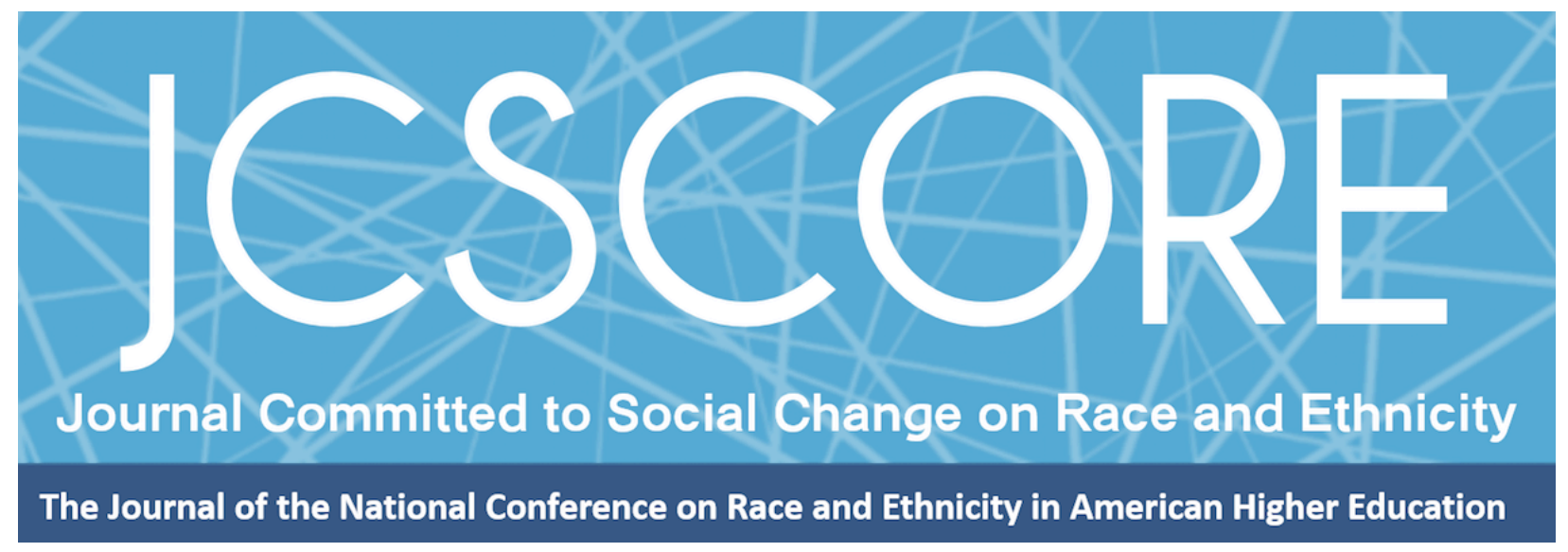

\title{
CREATING INCLUSIVE ENVIRONMENTS: THE MEDIATING EFFECT OF FACULTY AND STAFF VALIDATION ON THE RELATIONSHIP OF DISCRIMINATION/BIAS TO STUDENTS' SENSE OF BELONGING
}

Sylvia Hurtado

University of California, Los Angeles

Adriana Ruiz Alvarado

University of California, Los Angeles

Chelsea Guillermo-Wann

Santa Barbara Unified School District

Journal Committed to Social Change on Race and Ethnicity

Volume 1, Issue 1 | 2015

Copyright $\odot 2015$ Board of Regents of The University of Oklahoma on behalf of the Southwest Center for Human Relations Studies.

Permission of the Publisher is required for resale or distribution and for all derivative works, including compilations and translations. Quoting small sections of text is allowed as long as there is appropriate attribution. 


\title{
Creating Inclusive Environments: The Mediating Effect of Faculty and Staff Validation on the Relationship of Discrimination/Bias to Students' Sense of Belonging
}

\author{
Sylvia Hurtado \\ University of California, Los Angeles \\ Adriana Ruiz Alvarado \\ University of California, Los Angeles \\ Chelsea Guillermo-Wann \\ Santa Barbara Unified School District
}

This study reexamines notions of student integration given continuing experiences of discrimination and bias on college campuses. Building on the scholarship on inclusion, the authors test the mediating effect of student experiences with faculty and staff validation on the relationship of discrimination and bias to students' sense of belonging. The Diverse Learning Environments Survey was used to assess the model among 20,460 students attending broad access and selective institutions. Results show direct effects of validating experiences with faculty and staff on students' sense of belonging, and that such experiences mitigate the effects of discrimination and bias. Creating inclusive environments for student development remains a responsibility of faculty and staff, which we rarely assess even as research begins to uncover principles for transformative practice.

A prevailing myth is that student engagement is the same as integration in college life, and students are deficient when campus reports show lower levels of engagement among low-income, first generation, or underrepresented groups compared to peers. Harper and Quaye $(2009 ; 2014)$ contend that it is entirely possible to be involved (Astin, 1984) but not engaged in optimally beneficial ways. We add that it is possible to be behaviorally engaged in college without truly being integratedaccepted as equals, recognized, respected and empowered as learners in a diverse community. That is, student engagement behaviors provide only a partial picture of what it means to be integrated in college life. To resist deficit assumptions, we must shift the 
Journal Committed to Social Change on Race and Ethnicity | 2015

focus to assess and reflect on more complex causes of inequality (Dowd \& Bensimon, 2015) and consider the continuous forms of discrimination and bias incidents that serve as barriers to integration. Moreover, assumptions of privilege embedded in academic and social activities go unrecognized when we assume all students have access to them, when in fact, students weigh these 'opportunities' against the realities of their lived experiences. For example, many low-income students did not participate in specific social and academic activities because they said they could not spare the funds for fees, appropriate clothes, class trips or technology for course assignments (e.g. laptops) (Hurtado, Gasiewki \& Alvarez, 2014). Feelings of exclusion, reminders of low socioeconomic status, and a resounding theme of invisibility based on class and race/ethnicity were a part of the daily experiences for underrepresented groups.

While peers play an important role in student integration at the undergraduate and graduate levels, faculty and staff play a critical role in devising inclusive educational environments and creating the conditions for student success (Figueroa, 2015; Harper \& Quaye, 2014; Hurtado, Alvarez, Guillermo-Wann, Cuellar \& Arellano, 2012). Unfortunately, we rarely assess faculty and staff values, behaviors, and much less, culturally responsive practices (Dowd \& Bensimon, 2015). Evaluating educators' actions from the standpoint of students is essential to understanding their impact on student experiences and desirable college outcomes. Building on theories of inclusion developed with underrepresented populations in mind, the purpose of this study is to examine whether students' experiences with faculty and staff can mitigate the effects of discrimination and bias on their sense of belonging in college. The implications of this 
Journal Committed to Social Change on Race and Ethnicity | 2015

study may help to shape assessment and the contours of transformative practice in working with a diverse student body.

\section{Toward Theories and Models of Inclusion}

The early models of student persistence (Bean \& Metzner, 1985; Tinto, 1993;

Astin, 1993) have been critiqued for failing to capture what it means to be "integrated" in college for racial/ethnic groups (Tierney, 1992; Hurtado \& Carter, 1997). Whereas integration was once monitored behaviorally as time spent in specific social and academic activities, researchers have drawn attention to the importance of a psychological dimension of integration—sense of belonging (Hurtado \& Carter, 1997; Hausman, Schofield, \& Woods, 2007; Strayhorn, 2012). Sense of belonging, as a psychological measure of integration in the college community and attachment to an institution, has been linked with persistence and can vary by race/ethnicity and class (Hausman, et al., 2007; Strayhorn, 2012; Ostrove \& Long, 2007; Langhout, Rosselli, \& Fienstein, 2007). While there are different predictors of sense of belonging for different racial groups (Inkelas, Zaneeta, \& Vogt, 2007), we sought to establish a distinction between concepts in inclusive models and explore mediation rather than moderation effects in this particular study.

Over the last two decades, considerable research has linked sense of belonging to the types of institution students' attend, transition to college (Hurtado, Han, Saenz, Espinosa, Cabrera \& Cerna, 2007), various measures of academic and social activities (Hoffman, Richmond, Morrow, \& Salomone, 2002; Johnson, Soldner, Leonard, \& Alvarez, 2007; Locks, Hurtado, Bowman, \& Oseguera, 2008; Maestas, Vaquera, \& Zehr, 2007; Nuñez, 2009; Strayhorn, 2008), faculty interaction (Hoffman et al., 2002; 
Johnson et al., 2007; Maestas et al., 2007; Nuñez, 2009), and multiple aspects of campus climate for diversity (Hurtado \& Carter, 1997; Johnson et al, 2007; Locks et al., 2008; Maestas et al., 2007; Nuñez, 2009; Strayhorn, 2008; Guillermo-Wann, 2012) and cultural affirmation (Museus \& Maramba, 2011). Both campus climate and sense of belonging are significant factors in college student retention and degree completion (Hausmann et al., 2007; Museus, Nichols, \& Lambert, 2008; Nora, Barlow, \& Crisp, 2005; Rhee, 2008). Therefore, some of the inclusive theoretical models of underrepresented students also include these experiences as an important determinant of persistence (Nora, 2003; Nora et al., 2005; Hurtado et al., 2012).

These same inclusive models also incorporate another less explored process of inclusion—validation. Rendón $(1994,2002)$ found that in spite of low levels of activity in the social aspects of the college experience, many students still showed signs of success. The theory of validation (1994) proposes that students are most likely to succeed in college if they are empowered and view themselves as capable learners through the academic and interpersonal development they undergo from interactions with institutional agents (Stanton-Salazar, 2010; Museus \& Neville, 2012), both inside and outside of the classroom. Validation involves demonstrations of recognition, respect, and appreciation for students and their communities by faculty and staff, and its positive impact on persistence has been demonstrated for some less traditional student populations, including underrepresented racial/ethnic groups and community college students (Barnett, 2006, 2011; Rendón, 2002). Rendón (1994) details two forms of validation: academic and interpersonal. Academic validation occurs when agents actively assist students to "trust their innate capacity to learn and to acquire confidence 
Journal Committed to Social Change on Race and Ethnicity | 2015

in being a college student" (p. 40). Agents foster interpersonal validation when they engage in students' personal development and social adjustment to college as well as provide social capital to navigate the institution (Museus \& Neville, 2012).

Studies of validation are still at a nascent stage, with very few quantitative studies existing on the topic (Barnett, 2006, 2011; Guillermo-Wann, 2012; Hurtado, Cuellar, \& Guillermo-Wann, 2011; Hurtado, Cuellar, Guillermo-Wann, \& Velasco 2010). Barnett (2006) developed measures of student perceptions of faculty validation and confirmed four measures (students are known and valued, good instruction, appreciation for diversity, and mentoring) that influence student integration and persistence in a community college. Expanding the operationalization of validation to include institutional agents other than instructors, Hurtado et al. (2011) tested measures that tap both into a students' sense of academic validation in the classroom and also general interpersonal validation through interactions with staff and faculty outside of the classroom. Students of Color experience lower levels of both forms of validation, compared to White students. In addition, significantly larger proportions of students indicate higher levels of interpersonal validation at four-year private institutions compared to two-year community colleges and four-year public universities; whereas academic validation is most prevalent amongst community college students and least amongst students at public four-year institutions (Hurtado et al., 2010). Furthermore, interpersonal validation has an inverse relationship with experiencing discrimination and bias for Black, Latina/o, and White undergraduates after accounting for pre-college, institutional, curricular and co-curricular involvement, and other aspects of campus climate (Guillermo-Wann, 2012). Measures of empathetic faculty understanding, faculty 
Journal Committed to Social Change on Race and Ethnicity | 2015

support and comfort, and perceived classroom support contribute to sense of belonging (Hoffman et al., 2002), suggesting that validation from faculty in and out of the classroom may contribute to sense of belonging. Finally, although sense of belonging has been used as a proxy for validation in previous research (Nora, Urick, \& Quijada Cerecer, 2011), it is conceptually distinct from validation processes in theory (Nora, 2003; Nora et al, 2005; Hurtado et al., 2012). We tested the relationships in these models in order to explicitly connect validation and sense of belonging while also empirically testing the unique role of faculty and staff in assisting student integration for students who are continual targets based on their social identities.

\section{Methods}

\section{Data Source and Sample}

The data for this study came from a combined sample from the 2010 pilot administration and the 2011 national administration of the Diverse Learning Environments (DLE) survey conducted by the Higher Education Research Institute (HERI) at the University of California, Los Angeles (UCLA). The survey was built on the concepts in the Mulitcontexual Model for Diverse Learning Environments (MMDLE)(Hurtado et al., 2012). A draft of the pilot survey was administered to students in focus groups at two and four-year colleges in early 2009 , and was subsequently revised. Both broad access and compositionally diverse selective institutions were selected for the pilot administration based on IPEDS data indicating differences in student diversity. The pilot was administered between December 2009 and May 2010. After further revisions to the instrument, the DLE first offered national administration between October 2010 and June 2011. The DLE was designed to measure institutional 
Journal Committed to Social Change on Race and Ethnicity | 2015

practices, experiences with the campus climate, and student outcomes at both broad access and selective institutions. (See www.heri.ucla.edu/dleoverview.php).

Over the two-year period, data were collected at 34 campuses that included 18 private institutions, three public community colleges, and 13 public four-year colleges and universities. The final sample size for this study was 20,460 students and was comprised of $14.5 \%$ freshmen, $26.3 \%$ sophomores, $32.1 \%$ juniors, and $27.1 \%$ seniors. The racial composition of the sample was 27.4\% Asian, 2.9\% Black, 20.5\% Latina/o, 0.3\% Native American, $41.6 \%$ White, and $7.3 \%$ Multiracial. The mean parent income range was from $\$ 40,000$ - $\$ 49,999$ and one-fifth of the sample was comprised of firstgeneration college students as defined by parental educational attainment. One quarter of the students in the study entered their institutions as transfer students and $13.1 \%$ of the sample was older than 24-years-old.

\section{Key Variables}

Appendix A lists the four constructs included in the study and the measures comprising each. The key dependent variable in the model is Sense of Belonging $(\alpha=0.89)$, which is a three-item latent construct based on Bollen and Hoyle's (1990) work on social cohesion. The construct captures the extent to which students feel they are members of their college, see themselves as members of the campus community, and feel a sense of belonging to their institution.

Discrimination and Bias $(\alpha=0.89)$ is of central concern to student experiences with the climate and was included as an exogenous measure. This eight-item latent construct represents forms of discrimination that often go unreported to campus authorities. The eight items are measured on a five-point Likert scale (1=never to 
Journal Committed to Social Change on Race and Ethnicity | 2015

$5=$ very often) capturing the frequency with which students witnessed discrimination, experienced discrimination in the form of verbal comments, written comments, exclusion, offensive visual images, and heard insensitive or disparaging remarks from staff, faculty, or other students.

To test whether validation mediates the effect of students' perceptions of a discriminatory climate on sense of belonging, two endogenous variables were included: Academic Validation in the classroom $(\alpha=0.87)$ and General Interpersonal Validation $(\alpha=0.87)$. Each of these measures is a six-item latent construct that has been validated using confirmatory factory analyses (Hurtado et al., 2011). The Academic Validation indicators are five-point Likert scale items that capture students' reporting of faculty behaviors intended to foster academic development, including how frequently faculty provided feedback, encouraged questions and participation in discussion, showed concern for their progress, and made students feel that their contributions are valued in class. The six items in the General Interpersonal Validation construct are four-point scales capturing the extent to which students agree that faculty and staff members at their institution take an interest in their development, recognize their achievements or potential to succeed and empower them to learn or get involved in campus activities.

\section{Analysis}

After preliminary work on descriptive statistics and missing data, EQS 6.1 was used to conduct structural equation modeling (SEM) for the primary model tests. SEM is an appropriate form of analysis because it allows for the simultaneous estimation of hypothesized relationships among variables while taking into account measurement 
Journal Committed to Social Change on Race and Ethnicity | 2015

error, allowing for the examination of both direct and indirect effects of the independent variables on multiple dependent variables.

Due to deviation from multivariate normality in the data (particularly since Discrimination and Bias is not normally distributed on college campuses), we opted to use the robust maximum likelihood method of estimating parameters. Robust methods take into account violations of statistical normality assumptions and provide more accurate inferences (Huber \& Ronchetti, 1981). Maximum likelihood estimation provides multiple goodness-of-fit measures to assess the overall model. For this study, it was inappropriate to rely solely on the traditional chi-square test because it is sensitive to sample size (Bentler \& Bonnet, 1980), so we relied on multiple fit indices for reviewing and improving the model-fit (Hu \& Bentler, 1999). Instead, for assessment of absolute fit we used the root mean square error of approximation (RMSEA), which is considered one of the most informative indices because it is sensitive to the amount of estimated parameters contained in the model (Hooper, Coughlan, \& Mullen, 2008). A good model should produce an RMSEA of less than 0.06 (Hu \& Bentler, 1999).

\section{Limitations}

Several limitations should be noted when interpreting the results of this study. First, data were collected for each participant at a single point in time, which limits the ability to draw causal conclusions. However, the directions of the paths are all grounded in theory and past research with longitudinal samples. Second, the campus climate is operationalized as experiences with discrimination and bias and does not capture all

five dimensions of the climate (Hurtado et al., 2012), only specific types of bias incidents and perceptions of exclusion. Finally, for model simplicity, we did not include variables 
Journal Committed to Social Change on Race and Ethnicity | 2015

that have been previously linked to sense of belonging, including precollege characteristics (Strayhorn, 2010; Maestas et al, 2007; Locks et al, 2008), and other social and academic experiences (Locks et al, 2008; Johnson et al., 2007; Maestas et al., 2007; Nuñez, 2009; Strayhorn, 2010).. Nonetheless, the study was intentional in testing only a particular piece of Nora's (2003) and the MMDLE model to demonstrate how a discriminatory climate, validation, and sense of belonging work in relation to one another.

\section{Results}

In accordance with mediation model techniques (Baron \& Kenny, 1986), we first tested direct effects on Sense of Belonging using a two-construct model with each of the three other constructs in the study. The two-construct model for Discrimination and Bias on Sense of Belonging produced fit values of $x^{2}=900 \mathrm{df}=36, p=0.000$;

RMSEA $=0.03 ; \mathrm{NFI}=.99 ; \mathrm{CFI}=0.99$ and a direct path of $\beta=-.11$. After establishing that all three direct paths to Sense of Belonging were significant $(p<.001)$, we proceeded to test the hypothesized mediation model by regressing Sense of Belonging on all constructs, while also testing the relationship between Academic Validation, General Interpersonal Validation and Discrimination and Bias. To improve the model fit, we added paths between error terms that were theoretically justified by reviewing recommended paths in LaGrange tests. The final model produced fit values of $x^{2}=6823.25, \mathrm{df}=209, \mathrm{p}=0.000$; RMSEA=0.06; NFI=.91; CFI=0.92, explaining $37 \%$ of the variance in students' Sense of Belonging. Most importantly, results show that the negative direct effect of

Discrimination and Bias on Sense of Belonging is substantially reduced and mediated by students' validation experiences. Table 1 shows the reduction of the direct effect of 
Discrimination and Bias from $\beta=-.11$ in the two construct model to $\beta=-.04(p<.001)$ in the mediation model, indicating that Academic and General Interpersonal Validation can mitigate the negative effects of a hostile climate on students' psychological sense of integration in college.

Table 1. Direct Effect and Indirect Effects in Sense of Belonging Models

\begin{tabular}{|c|c|}
\hline Path & Standardized Coefficient \\
\hline \multicolumn{2}{|l|}{ Two Construct Model } \\
\hline \multicolumn{2}{|l|}{ Direct effect on Sense of Belonging } \\
\hline Discrimination and Bias & $-0.11 * * *$ \\
\hline \multicolumn{2}{|l|}{ Final Structural Model } \\
\hline \multicolumn{2}{|l|}{ Direct effect on Academic Validation } \\
\hline Discrimination and Bias & $-0.14 * * *$ \\
\hline \multicolumn{2}{|c|}{ Direct effect on General Interpersonal Validation } \\
\hline Discrimination and Bias & $-0.11 * * *$ \\
\hline \multicolumn{2}{|l|}{ Direct effect on Sense of Belonging } \\
\hline Discrimination and Bias & $-0.04 * * *$ \\
\hline Academic Validation & $0.05^{* *}$ \\
\hline General Interpersonal Validation & $0.60^{* * *}$ \\
\hline \multicolumn{2}{|l|}{ Indirect effect on Sense of Belonging } \\
\hline Discrimination and Bias & $-0.07 * *$ \\
\hline
\end{tabular}

Table 1 shows the coefficient estimates of direct and indirect paths. For simplicity, Figure 1 shows only the significant standardized coefficients for each of the direct paths in the mediation model. Confirming prior research models linking climate with sense of belonging (Locks et al., 2008; Hurtado \& Carter, 1997; Nuñez, 2009), the direct relationship between Discrimination and Bias and Sense of Belonging is negative $(\beta=-.04, p<.001)$. The direct paths from Academic Validation $(\beta=.05, p<.01)$ and General Interpersonal Validation $(\beta=.60, p<.001)$ to Sense of Belonging are both positive, indicating the more validation students receive both inside and outside of the 
classroom from faculty and staff, the greater their feelings of belonging to the campus community. This latter finding has only been theorized in inclusive models (Nora, 2003) and up to this point, had not been empirically tested across institutions.

Figure 1. Mediation model between Discrimination/Bias, Validation, and Sense of Belonging

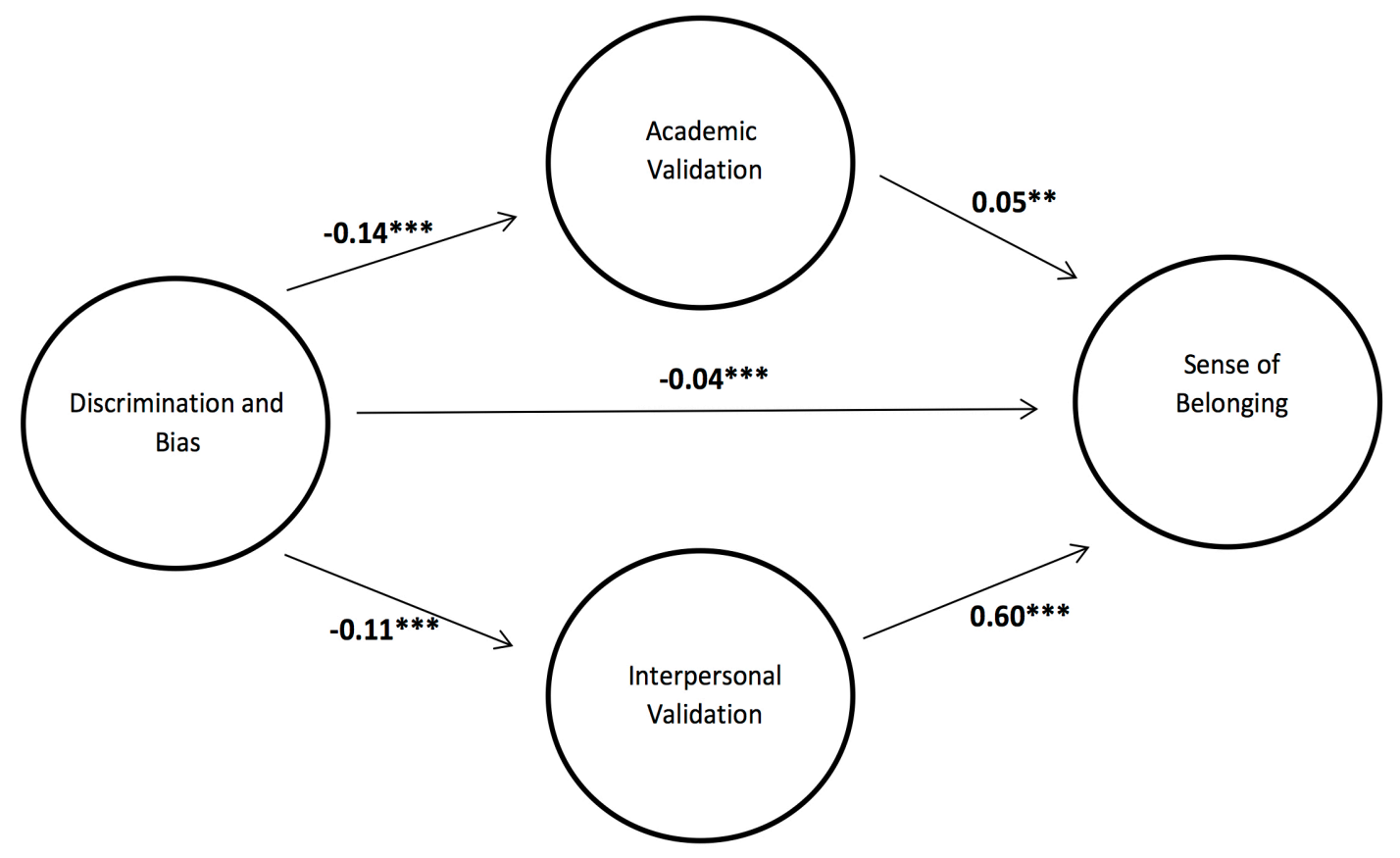

Results show the direct path is considerably stronger from General Interpersonal Validation than Academic Validation to Sense of Belonging, indicating distinctions between measures of validation that influence students' psychological sense integration. A student' sense of belonging might have more to do with the reception of a message than with the interactions reported since Academic Validation mostly captures student reports of behavior intended to foster academic development while General Interpersonal Validation captures students' interpretations of those behaviors in terms of support. For example, faculty feedback to help students assess their progress is a form of engagement in the Academic Validation construct but students may not always feel 
Journal Committed to Social Change on Race and Ethnicity | 2015

such feedback is constructive. Students' view of whether faculty are taking an active interest in their development is captured by the General Interpersonal Validation measure. Differences in the effects of these measures begin to suggest that students' interpretation of faculty and staff behavior is valuable to their integration in the campus community.

Discrimination and Bias has a negative direct effect on Academic Validation ( $\beta=$ $.14, p<.001)$ and General Interpersonal Validation $(\beta=-.11, p<.001)$. That is, the higher the level of discrimination and bias in students' experience, the less they engage and feel validated. Although it intuitively makes sense, it is nonetheless troubling because underrepresented students tend to have more negative experiences with the climate (Hurtado, 1992; Cabrera \& Nora, 1994; Rankin \& Reason, 2005; Hurtado \& Ruiz, 2012), and may consequently be less likely to reap the positive benefits of validation by institutional agents. This is evident in the indirect effect results: Discrimination and Bias had a negative $(\beta=-.07, p<.01)$ indirect effect on Sense of Belonging via its effect on both Academic Validation and General Interpersonal Validation. In other words, the more students witness acts of discrimination or hear disparaging remarks from faculty, staff, or fellow students, the less validated they are likely to feel, and consequently, the lower their sense of belonging on campus. Conversely, the efforts made by concerned institutional agents to help students feel more empowered--a sense of validation--can fortify students against discriminatory experiences and help them feel included as part of their campus communities. Implications of these findings are discussed in the next section. 


\section{Conclusion and Implications}

This study makes several important contributions to our understanding of creating inclusive communities on campus. First, it extends the generalizability of previous studies of validation by examining two new empirical measures of validation (academic and general interpersonal validation) across students attending broad access and selective institutions. The early work was conducted primarily on students attending community colleges, and this study extends the research to students attending four-year colleges. The availability of validation measures on the DLE survey enables the use of these constructs across institutions, opening a new path for researchers and institutions to assess validation experiences on campus. The work also extends previous qualitative research on both validation and the critical role of institutional agents in adjustment and navigation of college (Rendón, 1994; Museus \& Neville, 2011; Stanton-Salazar, 2010) and adds to the emerging quantitative research in this area by extending the definition of validation to include not just students' perceptions of how faculty empower them, but also how other institutional agents do so. This work suggests educators that have direct contact with students play an important role in creating students' sense of belonging on a campus. For students who do not have time for traditional college involvements or do not have as much peer contact, it is important to note they get their cues from faculty and staff about whether the educational environment is inclusive and welcoming.

Second, we hypothesized validation mediates the impact of discrimination and bias on students' sense of belonging. Previous research has well established the negative direct effect of a hostile racial climate on students' sense of belonging. We extend this work to show that while there are direct and indirect effects of discrimination 
and bias on students' sense of belonging, validating experiences help to offset these experiences: students who reported validating experiences were also less likely to report experiences of discrimination and bias, and the direct effect of discrimination and bias on sense of belonging was diminished after accounting for validating experiences. The validating experiences can reinforce self-worth and value in educational environments that may help students remain resilient despite microaggressions and assaults on their social identity. Further research is needed addressing cultural affirmation (Museus \& Maramba, 2011) and resilience in its relation to sense of belonging and ultimately student retention.

This brings us to a third contribution to research and practice: Findings begin to disentangle the concepts of validation and sense of belonging as two theoretically distinct internal psychological processes related to contexts and contacts with others in the educational environment. Validation is a process that involves recognition and value engendered by faculty and staff in curricula and extracurricular contexts. Sense of belonging is a feeling of attachment and place within the overall campus community. Both are critical as precursors to persistence in college. Future research should test each concept to determine if they have distinct effects on reenrollment and eventual graduation for different populations. Now that there are several measures available on national surveys of the Higher Education Research Institute, we can assess student experiences with faculty and staff in order to intentionally build inclusive learning environments and improve college degree attainments.

It is not a stretch to think that educators play a key role in recognizing, respecting and empowering students as members of the campus community. However, we still do 
little to assess and train faculty and staff to engage in principles of transformative practice even though we have years of research and theory to guide us. Transformative practices share some of the key goals and assumptions of transformative research (Hurtado, 2015), including 1) an ethic of care, respect, and advocacy for marginalized communities; 2) acknowledgement of multiple realities and unequal legitimacy of those perspectives on campus; and 3) incorporation of different ways of knowing and cultural values; as well as varied responses to daily forms of discrimination on campus and in society. Working to build resilient and empowered students who feel integrated should drive practice while we also focus on educating others to diminish bias and discrimination on campus. 


\section{References}

Astin, A. W. (1993). What matters in college? Four critical years revisited. San Francisco: Jossey-Bass.

Barnett, E. (2006). Validation experiences and persistence among urban community college students. Available from ProQuest Dissertations and Theses database. (UMI No. 3250210)

Barnett, E. A. (2011). Faculty validation and persistence among nontraditional community college students. Enrollment Management Journal, 5(2), 97-117.

Baron, R.M., \& Kenny, D.A. (1986). The moderator-mediator variable distinction in social psychology research: Conceptual, strategic, and statistical considerations. Journal of Personality and Social Psychology, 51, 1173-1182.

Bean, J., \& Metzner, B. (1985). A conceptual model of nontraditional undergraduate student attrition. Review of Educational Research, 55, 485-650.

Bentler, P.M., \& Bonnet, D.C. (1980). Significance tests and goodness of fit in the analysis of covariance structures. Psychological Bulletin, 88(3), 588-606.

Bollen, K. A., \& Hoyle, R. H. (1990). Perceived cohesion: A conceptual and empirical examination. Social Forces, 69(2), 479-504.

Cabrera, A. F. \& Nora, A. (1994). College students' perceptions of prejudice and discrimination and their feelings of alienation: A construct validation approach. Review of Education, Pedagogy, and Cultural Studies, 16(3-4), 387-409.

Dowd, A,C., \& Bensimon, E. M. (2015). Engaging the "race question": Accountability and equity and U.S. higher Education. New York: Teachers College Press.

Figueroa, T. (2015). Underrepresented racial/ethnic minority (URM) graduate students in science, technology, engineering, and math (STEM) disciplines: A cross institutional analysis of their experiences. Unpublished dissertation, University of California, Los Angeles.

Guillermo-Wann, C. (2012). (Mixed) race matters: Racial theory, classification, and campus climate. Available from ProQuest Dissertations and Theses database. (UMI No. 3548168)

Harper, S., \& Quaye, S. J. (2009;2014) Student engagement in higher education: Theoretical perspectives and practical approaches for diverse populations. New 
Journal Committed to Social Change on Race and Ethnicity | 2015

York: Routledge.

Hausmann, L. R., Schofield, J. W., \& Woods, R. L. (2007). Sense of belonging as a predictor of intention to persist among African American and White first-year college students. Research in Higher Education, 48(7), 803-839.

Hoffman, M., Richmond, J., Morrow, J., \& Salomone, K. (2002). Investigating sense of belonging in first-year college students. Journal of College Student Retention: Research, Theory \& Practice, 4(3), 227-256.

Hooper, D., Coughlan, J., \& Mullen, M.R. (2008). Structural equation modeling: Guidelines for determining model fit. Electronic Journal of Business Research Methods, 6(1), 53-60.

Huber, P.J., \& Ronchetti, E.M. (1981) Robust statistics. New York: Wiley.

Hurtado, S. (2015). The transformative paradigm: Principles and challenges. In A.

Aleman, B.P. Pusser, \& E. Bensimon. (Eds.) Critical approaches to the study of higher education. Baltimore, MD: Johns Hopkins University.

Hurtado, S. (1992). The campus racial climate: Contexts of conflict. Journal of Higher Education, 63(5), 539-569.

Hurtado, S., Alvarez, C. L., Guillermo-Wann, C, Cuellar, M., \& Arellano, L. (2012). A model for diverse learning environments: The scholarship on creating and assessing conditions for student success. In J.C. Smart, \& M.B. Paulsen (Eds.) Higher Education: Handbook of Theory and Research, 27. New York: Springer. Hurtado, S., \& Carter, D. F. (1997). Effects of college transition and perceptions of campus climate on Latino college students' sense of belonging. Sociology of Education, 70, 324-245.

Hurtado, S., Cuellar, M., \& Guillermo-Wann, C. (2011). Quantitative measures of students' sense of validation: Advancing the study of diverse learning environments. Enrollment Management Journal, 5(2), 53-71.

Hurtado, S., Cuellar, M., Guillermo-Wann, C., \& Velasco, P. (2010, May). Empirically defining validation, sense of belonging, and navigational actions for students in diverse institutions: The Diverse Learning Environments survey. Presentation at the Annual Forum for the Association for Institutional Research, Chicago, IL. Hurtado, S., Gasiewski, J. \& Alvarez, C.L. (2014). The climate for diversity at Cornell 
Journal Committed to Social Change on Race and Ethnicity | 2015

University: Student experiences. Retrieved May 5, 2015 from Cornell website: diversity.cornell.edu/sites/default/files/Qualitative-Study-of-the-Student-ClimateFull-Report.pdf.

Hurtado, S., Han, J.C., Saenz. V.B., Espinosa, L., Cabrera, N., \& Cerna, O. (2007).

Predicting transition and adjustment to college: Biomedical and behavioral science aspirants' and minority students' first year of college. Research in Higher Education, 48 (7), 841-887.

Hurtado, S., \& Ruiz, A. (2012). The climate for underrepresented groups and diversity on campus. Los Angeles, CA: Higher Education Research Institute.

Hu, L.T., \& Bentler, P.M. (1999). Cutoff criteria for fit indexes in covariance structure analysis: Conventional criteria versus new alternatives. Structural Equation Modeling, 6(1), 1-55.

Inkelas, K. K., Zaneeta, E. D., Vogt, K. E., \& Leonard, J. B. (2007). Living-learning programs and first-generation college students' academic and social transition to college. Research in Higher Education, 48(4), 403-434.

Johnson, D. R., Soldner, M., Leonard, J. B., \& Alvarez, P. (2007). Examining sense of belonging among first-year undergraduates from different racial/ethnic groups. Journal of College Student Development, 48(5), 525-542.

Langhout, R. D., Rosselli, F., \& Feinstein, J. (2007). Assessing classism in academic settings. Review of Higher Education, 30(2), 145-184.

Locks, A. M., Hurtado, S., Bowman, N. A., \& Oseguera, L. (2008). Extending notions of campus climate and diversity to students' transition to college. Review of Higher Education, 31(3), 257-285.

Maestas, R., Vaquera, G. S., \& Zehr, L. M. (2007). Factors impacting sense of belonging at a Hispanic- serving institution. Journal of Hispanic Higher Education, 6(3), 237-256.

Museus, S.D., \& Maramba, D.C. (2011). The impact of culture on Filipino American students' sense of belonging. Review of Higher Education, 34(2), 231-258.

Museus, S. D., Neville, K. (2012). The role of institutional agents and social capital in the experiences of minority college students. Journal of College Student Development, 53(3), 436-452. 
Museus, S. D., Nichols, A. H., \& Lambert, A. D. (2008). Racial differences in the effects of campus racial climate on degree completion: A structural equation model. Review of Higher Education, 32(1), 107-134.

Nora, A. (2003). Access to higher education for Hispanic students: Real or illusory? In J. Castellanos \& L. Jones (Eds.), The majority in the minority: Expanding the representation of Latina/o faculty, administrators, and students in higher education (pp. 47-68). Sterling: Stylus.

Nora, A., Barlow, E., \& Crisp, G. (2005). Student persistence and degree attainment beyond the first year in college. In A. Seidman (Ed.), College retention: Formula for student success (pp. 129-153). Westport, CT: ACE/Praeger.

Nora, A., Urick, A., \& Quijada Cerecer, P.D. (2011). Validating students: A conceptualization and overview of its impact on student experiences and outcomes. Enrollment Management Journal, 5(2), 53-71.

Nuñez, A. (2009). Latino students' transitions to college: A social and intercultural capital perspective. Harvard Educational Review, 79(1), 22-48.

Ostrove, J. M., \& Long, S. M. (2007). Social class and belonging: Implications for college adjustment. Review of Higher Education, 30(4), 363-389.

Rankin, S., \& Reason, R. (2005). Differing perceptions: How students of color and White students perceive campus climate for underrepresented groups. Journal of College Student Development, 46(1), 43-61.

Rendón, L. I. (1994). Validating culturally diverse students: Toward a new model of learning and student development. Innovative Higher Education, 27(4), 235-252.

Rendón, L. I. (2002). Community college Puente: A validating model of education. Journal of Educational Policy, 16(4), 642-667.

Rhee, B. (2008). Institutional climate and student departure: A multinomial multilevel modeling approach. The Review of Higher Education, 31(2), 161-183.

Stanton-Salazar, R. D. (2010). A social capital framework for the study of institutional agents and their role in the empowerment of low-status students and youth. Youth \& Society, 10(5), 1-44.

Strayhorn, T.L. (2012). College students' sense of belonging: A key to educational success for all students. New York: Routledge. 
Journal Committed to Social Change on Race and Ethnicity | 2015

Strayhorn, T. L., (2008). Sentido de pertenencia: A hierarchical analysis predicting sense of belonging among Latino college students. Journal of Hispanic Higher Education, 7, 301-320.

Strayhorn, T.L. (2010). When race and gender collide: Social and cultural capitals' influence on the academic achievement of African American and Latino males. The Review of Higher Education, 33(3), 307-332.

Tierney, W.G. (1992). An anthropological analysis of student participation in college. Journal of Higher Education, 63(6), 603-617.

Tinto, V. (1993). Leaving college: Rethinking the causes and cures of student attrition (2nd ed.). Chicago: University of Chicago Press. 
Journal Committed to Social Change on Race and Ethnicity | 2015

\section{Appendix A. Measurement Model}

\begin{tabular}{lc}
\hline Manifest Variable & $\begin{array}{c}\text { Standardized } \\
\text { Coefficient }\end{array}$ \\
\hline Discrimination and Bias ( $\alpha=0.89)$ & $0.811^{* *}$ \\
Experienced discrimination type: verbal comments & $0.738^{* *}$ \\
Experienced discrimination type: written comments & $0.731^{*}$ \\
Experienced discrimination type: offensive visual images & $0.725^{* *}$ \\
Experienced discrimination type: exclusion & $0.709^{* *}$ \\
Witnessed discrimination & $0.664^{*}$ \\
Heard insensitive or disparaging remarks from: faculty & $0.659^{*}$ \\
Heard insensitive or disparaging remarks from: staff & $0.613^{* *}$ \\
Heard insensitive or disparaging remarks from: students & \\
& \\
Academic Validation in the Classroom ( $\alpha=0.87)$ & $0.845^{*}$ \\
I feel like my contributions were valued in class & $0.840^{* *}$ \\
Instructors provided me with feedback that helped me judge my progress & $0.773^{* *}$ \\
Instructors were able to determine my level of understanding of course material & $0.765^{*}$ \\
Instructors encouraged me to ask questions and participate in discussions & $0.521^{* *}$ \\
Instructors showed concern about my progress & $0.471^{* *}$ \\
Instructors encouraged me to meet with them after or outside of class & \\
& \\
General Interpersonal Validation ( $\alpha=0.87)$ & $0.799^{* *}$ \\
Faculty believe in my potential to succeed academically & $0.762^{* *}$ \\
At least one faculty member has taken an interest in my development & $0.755^{* *}$ \\
At least one staff member has taken an interest in my development & $0.752^{* *}$ \\
Staff recognize my achievements & $0.623^{*}$ \\
Faculty empower me to learn here & $0.577^{*}$ \\
Staff encourage me to get involved in campus activities & \\
& \\
Sense of Belonging ( $\alpha=0.89$ ) & $0.854^{* *}$ \\
I see myself as part of the campus community & $0.860^{* *}$ \\
I feel I am a member of this college & $0.821^{* *}$ \\
I feel a sense of belonging to this campus &
\end{tabular}

$* * \mathrm{p}<.01,{ }^{*} \mathrm{p}<.05$ 